\title{
PREVALENCE OF COVID -19 PANDEMIC: A PARADIGM SHIFT TO HYDROGEN ECONOMY
}

\section{*MUHIBBUDIN ENIOLA ISMAIL, ADEPOJU MUEEZ OLARENWAJU, SANNI MUBARAK, OKOROJI VICTOR, BASSEY DORCASS ASUQUO}

Chemical Engineering Department, University of Ilorin

*Email: muhibbudin.ei@unilorin.edu.ng

Received: $13^{\text {th }}$ May 2020

Accepted: $15^{\text {th }}$ June 2020

Published: $20^{\text {th }}$ September 2020

https://doi.org/10.47545/etrj.2020.5.2.068

\begin{abstract}
Covid-19 pandemic lockdown has slowed down the world economic system. The pandemic has cleared the roads, close factories and grounded planes causing severe economic challenges. The damaging impact of the pandemic amid lockdown has been a blessing in guise for the environment because of significant drop in pollution level as transport and industrial sectors shutdown. Transport and industrial sectors are major contributors to environmental degradation through various emissions as a result of fossil fuel consumption. Energy consumed by transport and industrial sectors will have to shift to viable, readily available, clean, storable, economically and environmentally friendly with no carbon build up post Covid-19 pandemic. Hydrogen energy remains the best alternative option technologies containing greenhouse gas emission and pollutions of several forms. Hydrogen holds the potential to provide a clean, reliable, renewable and economical source of energy for meeting the growing and unending global energy needs post pandemic. The present paper explores prospect of hydrogen gas energy to serve as a competitive fuel option post pandemic and the economic feasibility. In this paper, the role of hydrogen as an energy carrier, hydrogen economy structure, potential of hydrogen economy, hydrogen production methods, hydrogen application and the economic and environmental significance of hydrogen as a viable fuel option post Covid-19 pandemic were thoroughly discussed. There will be a surge in demand and investment for hydrogen economy post Covid-19 to achieve decarbonization of transport and industrial sectors.
\end{abstract}

Keywords: Corona virus, Degradation, Hydrogen economy, Clean energy, Renewable, Environmental impact.

\section{INTRODUCTION}

Since December 2019, there has been outbreak of novel corona virus named covid-19 reported to have emerged from Wuhan in china. The disease continued to spread from China to many other parts of the world, affecting 196 countries by March 25, 2020 [1]. This spread aroused the attention of everyone worldwide.

The transmission of the virus is from person to person through contacts influenced by environmental factors such as climatic conditions, population's concentration and medical quality [3]. In order to curtailed and controlled the spread of Covid-19, many cities in the world lockdown completely. Majority of roads, factories/industries and airport have been grounded in ordered to significantly reduce person to person contact and transmission. The consequent of the decision to lockdown resulted in dramatic improvement in the pollution level of air, water and soil quality. The global weather condition becomes better and the skies become blue and clearer. Covid-19 seems to be a blessing in disguise for the environment and implying that transport and industrial sectors are major contributors to global pollutions. Transport and industrial sectors have direct impact on global energy consumption. Restriction of both sectors have brought down current oil demand and consequently lowered greenhouse gases. NASA satellite image have shown that pollutions level reduces remarkably in Chinese cities, Western Europe, United States and Iran over the lockdown [4] and suggesting that there must be a paradigm shift in world energy demand for a cleaner and greener energy after the lockdown when transport and industrial sectors will be opened. Therefore, a shift toward hydrogen economy is inevitable. Hydrogen energy have the potential to redefine global energy landscape, providing options beyond oil and coal which have caused environmental degradation, issues on climate change and concerned for human health. 
Hydrogen economy will bring about a balance in economic goal, lower pollution level which can help the most vulnerable fight against future pandemic. Hydrogen energy is the best alternative energy to oil, coal and nuclear energy.

\subsection{Hydrogen as energy carrier}

Hydrogen is an abundant element on earth but not naturally occurring. Its combine with other element to form many common materials. It exists in water, hydrocarbon, coal, petroleum, natural gas, oil shale, biological material, carbohydrate, cellulose and protein. Hydrogen is not a primary energy source but alternative replacement to fossil fuel. With hydrogen energy technology, zero carbon foot print can be achieved from transport and industrial operations. As fascinating energy carrier, it can be produced from electricity and water. When combusted with oxygen, its form water and the water is return to nature. Little or no pollutants are generated or emitted. Currently, hydrogen is majorly produced as chemical feedstock. According to USDOE (2002) [5] nine million ton of hydrogen are consumed annually in chemical production, petroleum refinery, metal treating and electrical applications in United States.

\subsection{Hydrogen economy structure}

Hydrogen economy is the system of production, distribution, consumption and utilization of hydrogen gas energy. It is composed of five segments: hydrogen production, storage, delivery, conversion and end-user applications. Fossil fuel, electricity and nuclear energy can be utilized to generate hydrogen through chemical, electrolytic, thermal and photolytic process. Hydrogen can be stored as liquid or gas and be delivering to pipelines, trucks, trains, airplane and barges. With hydrogen gas as alternative energy air, water and soil quality will improve without any pollution as experienced during covid-19 lockdown.

\subsection{Potentials of hydrogen economy}

Currently energy sources are dominated by fossils fuels (coal, oil and gas) and are considered as largest source anthropogenic emissions of greenhouse gases particularly carbon dioxide into the atmosphere that is largely responsible for global warming and climate change [6]. Increasing fossil fuel consumption has brought serious problems to the world including intractable energy security [7], green house emission [8] and air pollution [9]. The impact of covid-19 around the world couple with global oil energy crisis, pollution and scarcity require the need to diversify and explore energy resources toward an alternative energy fuel. The alternative fuel must be clean, technically feasible, economically competitive, environmentally friendly, readily available [10] with no negative issues on human health, public and environmental welfare. Numerous potential alternative fuels have been proposed which include biodiesel, methanol, ethanol, hydrogen, boron, natural gas, liquefied petroleum gas (LPG), FischerTropsch fuel, p-series, electricity and solar fuel [11]. Among all of these alternative fuels, hydrogen has the highest specific energy content of all conventional fuels [12] and is the most abundant element in the universe. Hydrogen economy is global solution to energy crisis/scarcity, air pollution health effects and global warming. Moreover, hydrogen can be generated or regenerated from variety of energy sources like coal, nuclear, wind, solar energy. Hydrogen thus offers the promise energy security and availability through great production and use of domestic energy resources. Eventually the world will run out fossil fuels and at that time the society will be force to transition of alternative fuel of hydrogen. Most importantly application of hydrogen energy in transport sector through fuel cell vehicles and industrial sector will improve urban and industrial air quality thereby reduces generation of photochemical smog in urban / industrial environment. Since transport and industrial sectors are major contributor to climate change which result to global warming but with wide application of onboard hydrogen fuel cell technology on transport and industrial sectors, zero emission will be achieve thereby hydrogen is a solution to global warming. Global market for hydrogen is already greater than $\$ 40$ billion per year [9]. This includes hydrogen used in ammonia production (49\%), petroleum refining (37\%), methanol production (8\%), and miscellaneous smaller-volume uses (6\%) (10). Present utilization of hydrogen is slightly above $3 \%$ of the energy consumption and with a growth rate estimated at $5-10 \%$ per year [13]. It can be foreseeing and predicted that hydrogen energy demand production and consumption will increase after Covid-19 pandemic. Australia and Germany governments have made tremendous investment in hydrogen supply pre covid-19 pandemic [14] and more investment will be done by first world countries post covid19 pandemic. 


\subsection{Properties of hydrogen as industrial and transport fuel.}

Hydrogen is a colourless, odourless, tasteless gas and nontoxic gas found in the air at concentration of about 100 ppm $(0.01 \%)$ [15]. It is the lightest known substance: it is 14.4 times less dense than air. It is the most abundant element in the universe although in combine form, making up to $75 \%$ of normal matter by mass and over $90 \%$ by number of atoms [16] to provide energy, hydrogen can be either burned or reacted chemically at very high conversion efficiency and will produce virtually little/no emissions. Like any other fuel source, hydrogen has both strengths and weaknesses based on its chemical and physical properties. Below are the properties of hydrogen compare to natural gas and gasoline as industrial and transport fuel:

Table I: Comparison of Properties of Hydrogen, Natural Gas and Gasoline

\begin{tabular}{|c|c|c|c|}
\hline Properties & Hydrogen & $\begin{array}{l}\text { Natural } \\
\text { Gas }\end{array}$ & Gasoline \\
\hline Molecular weight $(\mathrm{g} / \mathrm{mol})$ & 2.016 & 16.04 & $\sim 110$ \\
\hline Mass density $\left(\mathrm{kg} / \mathrm{N}_{\mathrm{A}} \mathrm{m}^{3}\right)$ at $\mathrm{P}=1, \mathrm{~T}=0^{\circ} \mathrm{C}$ & 0.09 & 0.72 & $720-780$ \\
\hline Mass density of liquid $\mathrm{H}_{2}$ at $20 \mathrm{~K}\left(\mathrm{~kg} / \mathrm{N}_{\mathrm{A}} \mathrm{m}^{3}\right)$ & 70.9 & - & - \\
\hline Boiling point $(\mathrm{K})$ & 20.2 & 111.6 & $310-478$ \\
\hline $\begin{array}{l}\text { Higher heating value }(\mathrm{MJ} / \mathrm{kg}) \text { (Assume water } \\
\text { is produced) }\end{array}$ & 142 & 55.5 & 47.3 \\
\hline $\begin{array}{l}\text { Lower heating value }(\mathrm{MJ} / \mathrm{kg}) \text { (Assume steam } \\
\text { is produced) }\end{array}$ & 120 & 50 & 44 \\
\hline Flammability limits (\% volume) & $4.0-75.0$ & $5.3-15.0$ & $1.0-7.6$ \\
\hline Detonability limits (\% volume) & $18.3-59.0$ & $6.3-13.5$ & $1.1-3.3$ \\
\hline Diffusion velocity in air $(\mathrm{m} / \mathrm{s})$ & 2 & 0.51 & 0.17 \\
\hline \multicolumn{4}{|l|}{ Ignition energy $(\mathrm{mJ})$} \\
\hline At stoichiometric mixture & 0.02 & 0.29 & 0.24 \\
\hline At lower flammability limit & 10 & 20 & not available \\
\hline Flame velocity in air $(\mathrm{cm} / \mathrm{s})$ & $265-325$ & $37-45$ & $37-43$ \\
\hline Toxicity & Nontoxic & Nontoxic & $\begin{array}{r}\text { Toxic above } 50 \\
\text { ppm } \\
\end{array}$ \\
\hline
\end{tabular}

Source: [11]

As an industrial and transport tend to seek fuel option while considering environmental concerns, hydrogen exhibits numerous advantageous properties including its high diffusion velocity, highest heating value of any fuel (per kilogram), wide range of flammability and detonability limits, low ignition energy, high flame speed, and nontoxicity. Because hydrogen diffuses very rapidly, it will disperse quickly from a leak, and doesn't form puddles that can explode.

Table 1 show that the heating value of fuels, or the amount of heat that is transferred from the complete combustion of fuels in air increases with the hydrogen to carbon ratio $(\mathrm{H} / \mathrm{C})$. Thus, gasoline has the lowest heating value and hydrogen the highest, and therefore a very high potential to do useful work in an engine. The broad range of flammability and detonability limits of hydrogen (the concentration of the fuel in air that can ignite or explode respectively) means that hydrogen does not have to be in stoichiometric ratios to be combusted; it can be burned in leaner concentrations leading to reduce fuel consumption. In other words, Hydrogen engines can be operated more effectively on excessively lean mixtures than gasoline engines. As little as $4 \%$ hydrogen by volume with air produces a combustible mixture [17] and Hydrogen can detonate over a very wide range of concentrations when confined, however, unlike many other fuels; it is very difficult to detonate if unconfined. 
Additionally, the energy required to ignite a mixture of hydrogen in air is low at stoichiometric mixture and lower flammability limit, 0.02 and $10 \mathrm{MJ}$ respectively. The flame speed of hydrogen is high, both factors which aid in the complete mixing and combustion of the fuel in a hydrogen combustion engine. The nontoxicity of hydrogen is also an added bonus when compared to gasoline or any other fuel. When looked at with its environmental friendliness, except for very small levels of NOx, hydrogen produces only water when burned or chemically reacted. Its physical properties make it an intriguing fuel option. However, hydrogen also has several drawbacks. Compared to natural gas and gasoline, hydrogen is a very low-density diatomic gas, and thus must be compressed to very high pressures, liquefied at a temperature of about $-252^{\circ} \mathrm{C}$, or stored in some other specialized fashion in order to condense a reasonable amount in a reasonable volume. As a compressed gas, hydrogen exhibits rather low energy density, containing about one-third the energy as an equivalent volume of natural gas at the same pressure and as a cryogenic liquid, about one-third the energy as an equivalent volume of gasoline. Hydrogen is also an extremely small molecule, diffusing more readily than other fuels, and is more likely to leak. Moreover, it can even diffuse into some metals and cause embrittlement therefore hydrogen systems thus necessitate special materials considerations. The lower flammability limit of hydrogen, above considered as a strength, also means that if hydrogen leaks and builds up in low concentrations in an enclosed space, accidental explosion can occur or if fuel and air mix outside the cylinder of an engine, backfiring can occur. Due to a high flame velocity, this explosion could also travel very rapidly. A potential solution to backfiring is direct injection of hydrogen gas into the cylinder prior to spark generation which also increases engine efficiency by allowing the engine to run at higher compression ratios than if it ran on gasoline. Nonetheless, backfiring remains a potential risk of a hydrogen combustion engine. Hydrogen clearly exhibits several attractive physical properties when it comes to fuel applications, but it is also important to remember its potential risks when implementing it in a industries and transport sector.

Laboratory tests conducted on internal combustion engines burning hydrogen demonstrate good performance [18]. In comparison with an engine burning gasoline, the emission of nitrogen oxides is far less for the engine-fueled hydrogen. The product of hydrogen combustion with air is water vapor and negligible pollution when the peak temperature is limited. Some oxides of nitrogen (NOx) are formed at very high combustion temperatures $(<2300 \mathrm{~K})$; fortunately, the auto ignition temperature of hydrogen is only $858 \mathrm{~K}$ [19]. The oxide of nitrogen $\left(\mathrm{NO}_{\mathrm{X}}\right)$ is form as a result of combustion of air with hydrogen mixture. The air is mixture of gases majorly $78 \%$ nitrogen and $21 \%$ of oxygen with very small amount of $\mathrm{CO}_{2}$, noble gases and water vapour. Hydrogen has good properties as a fuel for internal combustion engines in automobiles. Some of the characteristic properties of a hydrogen-air mixture that can definitely influence the engine design and performance are low ignition energy, low ignition energy, low density, wide range of ignition limits, high diffusion speed, and high flame speed [19].

\subsection{Sources of hydrogen}

Hydrogen can be source from variety of primary energy such as fossil fuels, nuclear [20], solar [21], wind [22], hydropower [23] and geothermal energy [24] Different energy resources with various pathways can be utilized to generate hydrogen. Various processes such as methane steaming steam reforming, water electrolysis, high temperature electrolysis, and thermochemical cycles are available to produce hydrogen as well. The main sources for commercial production of hydrogen include natural gas (48\%), oil (30\%) coal (18\%) and electrolysis (4\%) of world hydrogen production [2]. Fossil fuels conversions are dominant source of commercial/industrial hydrogen such as natural gas reforming [25]..

With respect to production capacities, hydrogen production can also be categorized into 'distributed' or 'centralized' production. Distributed production facilities are smaller in scale and closer to the consumers. As such distributed generations can meet the demand from transportation sector of hydrogen powered fuel cell vehicles during the transition period to a hydrogen economy and once the market expands, the hydrogen production will be scaled up and 'centralized' to take advantage of economies of scale as well as the higher efficiency from larger scale production and to meet the greater amount of hydrogen demand in industrial sector.

\section{MATERIALS AND METHODS}

\subsection{Hydrogen Production Processes/Methods}

Steam reforming of natural gas: Steam methane reforming (SMR) is a process in which the natural gas or other methane streams, such as biogas or landfill gas, reacts with steam in the presence of a catalyst (usually nickel) to 
produce hydrogen and carbon monoxide. It is worth mentioning that, natural gas reforming produces for more than $90 \%$ of hydrogen production worldwide and remains the most commonly used method for hydrogen production. This process consists of heating the gas to between $700-1100{ }^{\circ} \mathrm{C}$ in the presence of steam and a nickel catalyst. The resulting endothermic reaction breaks up the methane molecules and forms carbon monoxide $\mathrm{CO}$ and hydrogen $\mathrm{H}_{2}$ [26].

$\mathrm{CH}_{4}+\mathrm{H}_{2} \mathrm{O} \rightarrow \mathrm{CO}+3 \mathrm{H}_{2}$

The carbon monoxide gas can then be passed with steam over iron oxide or other oxides and undergo a water gas shift reaction to obtain further quantities of $\mathrm{H}_{2}$.

$\mathrm{CO}+\mathrm{H}_{2} \mathrm{O} \rightarrow \mathrm{CO}_{2}+\mathrm{H}_{2}$

The downside to this process is that its major by-products are $\mathrm{CO}, \mathrm{CO}_{2}$ and other greenhouse gases. Depending on the quality of the feedstock (natural gas, rich gases, naphtha, and others), one ton of hydrogen produced will also produce 9 to 12 tons of $\mathrm{CO}_{2}$.

According to the Director of Energy of USA (2017) [27], SMR is approximately 72\% efficient in hydrogen generation when starting with natural gas. Conversely, on a lower heating value basis. SMR produces a hydrogen-rich gas that is typically on the order of 70-75\% hydrogen on a dry mass basis, along with smaller amounts of methane (2-6\%), carbon monoxide (7-10\%), and carbon dioxide (6-14\%) [28].

In addition, SMR is not an attractive production route for a developed hydrogen economy. This is due to the fact that the order-of-magnitude increase in demand would deplete our finite reserves. Moreover, the concentration of gas reserves in relatively few regions of the world could lead to geopolitical tension and unstable supplies. Environmental impact is also a major concern because reforming natural gas to hydrogen produces as much pollution and $\mathrm{CO}_{2}$ as burning the natural gas directly. Generation of hydrogen from natural gas is a well-established process. If sufficient quantities are produced to power the world's cars and light trucks it would strain the world's supply of conventional methane, making natural gas as geopolitically sensitive as an oil [28].

\subsection{Gasification of Coal and other Hydrocarbons:}

Currently, gasification processes are mainly used in large-scale integrated gasification combined cycle power plants (due to the low flexibility of synthesis gas production) in order to supply base energy load. But in a short-term future, the possibility to produce hydrogen from syngas could make gasification technologies very interesting also for medium and small-scale industrial applications. To this aim, Sotacarbo, Ansaldo Ricerche,ENEA and the Department of Mechanical Engineering of the University of Cagliari developed an integrated gasification and syngas treatment process for combined production of hydrogen and electrical energy for medium and small-scale commercial applications [29].

The partial oxidation process termed as "gasification", generates hydrogen from a wide range of hydrocarbon fuels, including coal, heavy residual oils, and low-value refinery products. In this process, the hydrocarbon fuel is made to react with oxygen in a less than the stoichiometric ratio, yielding a mixture of carbon monoxide and hydrogen at 1200 to $1350^{\circ} \mathrm{C}$ [28]. Coal is a practical option for making hydrogen in large plants. Worldwide coal reserves and commercially available technologies make coal a practical option for producing hydrogen in large plants. Compared to the existing methods (i.e. electrolysis), gasification is more suitable for converting coal to hydrogen [30].

The process begins with partial oxidation, which means some air is added to the coal, which generates carbon dioxide gas through traditional combustion. Not enough is added, though, to completely burn the coal (only enough to make some heat for the gasification reaction). The partial oxidation also makes its own gasification agent, carbon dioxide. Carbon dioxide reacts with the rest of the carbon in the coal to form carbon monoxide (this is the endothermic gasification reaction, which needs heat input). No hydrogen yet.

Carbon monoxide in the gas stream is now further reacted with steam, generating hydrogen and carbon dioxide. Now we are making some hydrogen. The hydrogen can then be run through an on-site fuel cell to generate high-efficiency electricity. Brown coals are generally preferred for gasification over black coals for several reasons. 
The main reason is that, because of the high oxygen content of this type of coal, it is less chemically stable and therefore easier to break apart during the gasification reaction. Also, there is a small boost from the hydrogen that is already present in the coal [31].

Hydrogen produced from this method is not a zero-emission fuel. Carbon dioxide is generated through the combustion and thermal decomposition reactions and is also a by-product of the reaction between carbon monoxide and water to make hydrogen and carbon dioxide.

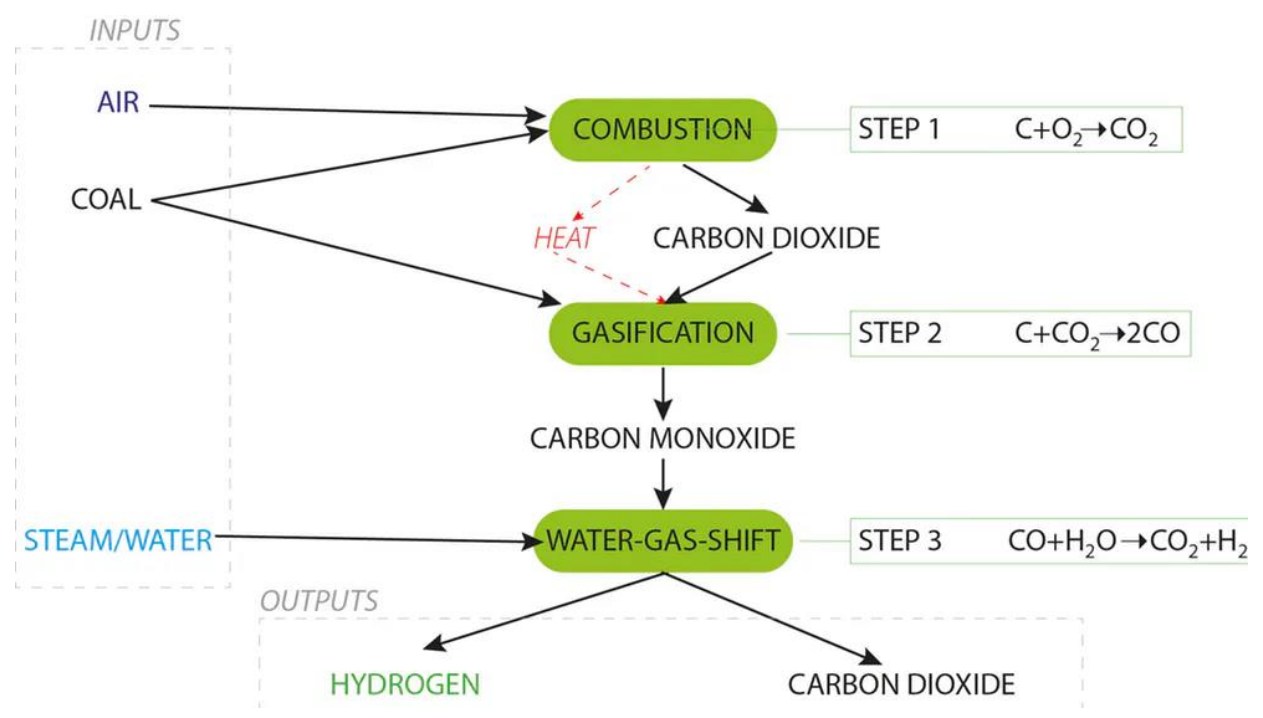

Figure 1. Production of Hydrogen from gasification of coal [31].

\subsection{Hydrogen Production from Nuclear Energy}

Thermochemical water splitting: Thermochemical water splitting uses high temperatures from nuclear power plant reactions to produce hydrogen and oxygen from water. Thermochemical water splitting processes use hightemperature heat $\left(500^{\circ} \mathrm{C}\right.$ or more) to initiate a series of chemical reactions that generate hydrogen. The chemicals used in the process are reused within each cycle, creating a closed-loop that uses up only water and produces hydrogen and oxygen.

Thermochemical water splitting cycles have a major advantage of not requiring catalysis to drive individual chemical reactions. Except for water, which is the material source of hydrogen production, all chemicals used in the thermochemical cycle can be recycled. Other advantages of thermochemical water splitting cycles are little or no need for $\mathrm{O}_{2}-\mathrm{H}_{2}$ separation membranes, reasonable temperature requirement range of $300-1000^{\circ} \mathrm{C}$ and zero or low electrical energy requirement. Being fully developed and demonstrated in Japan and the US, the S-I cycle (SulfurIodine cycle) is considered as technically viable. Though there are numerous setbacks associated with this method of hydrogen production. The first reaction of S-I a cycle is thermally driven and it can be written as:

$\frac{\text { Heat } 300-500^{\circ} \mathrm{C}}{\mathrm{H}_{2} \mathrm{SO}_{4(a q)} \rightarrow \mathrm{H}_{2} \mathrm{O}_{(g a s)}}+\mathrm{SO}_{3(g)}$

The product gases $\left(\mathrm{H}_{2} \mathrm{O}\right.$ and $\left.\mathrm{SO}_{3}\right)$ are separated heated up to 800-900C. Then $\mathrm{SO}_{3}$ gas is decomposed thermally according to the following equation.

Heat $800-900^{\circ} \mathrm{C}$

$\mathrm{SO}_{3(g)} \rightarrow \quad \overline{2} \mathrm{O}_{(g)}^{-}+\mathrm{SO}_{2(g)}$ 
After separation from $\mathrm{O}_{2}, \mathrm{SO}_{2}$ undergoes an exothermic reaction with iodine and water which occurs at low temperatures spontaneously:

$\mathrm{SO}_{2(g)}+\mathrm{I}_{2(g)}+2 \mathrm{H}_{2} \mathrm{O}_{(l)} \rightarrow 2 \mathrm{HI}_{(g)}+\mathrm{H}_{2} \mathrm{SO}_{4(a q)}$

Lastly, $\mathrm{HI}$ thermally decomposes into $\mathrm{H}_{2}$ at temperatures around $420-450^{\circ} \mathrm{C}$ :

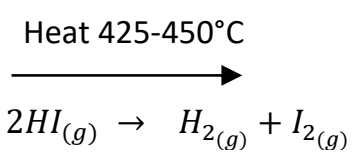

Since there are no side reactions happening during the S-I cycle, it is reasonably straightforward to separate and reuse the chemicals used in Reactions (3)-(6). Because of the relatively high reaction temperature requirements of S-I cycles, there are not many sustainable thermal energy sources available to drive the individual reactions in the cycle. Nuclear, concentrated solar, and biomass combustion heat can be listed as possible sustainable thermal energy sources to drive the S-I cycle reactions. In the hybrid version of S-I cycles, the hydrogen-generating reaction is supported electrochemically [38].

\subsection{Hydrogen Production from Renewable Energy}

Biomass gasification: Biomass sources such as wood and agricultural products, solid wastes, landfill gas and biogas, ethanol, biodiesel and so on can be processed for the production of hydrogen. Biomass conversion technologies are divided into two categories: thermo-chemical and biochemical processes. Thermochemical processes tend to be less expensive because they can be operated at higher temperatures and therefore achieve higher reaction rates. They involve either gasification or pyrolysis (heating biomass in the absence of oxygen) to produce a hydrogen-rich stream of gas known as "syngas" (a blend of hydrogen and carbon monoxide) ([28]. Though biomass gasification has not been able to produce hydrogen on a large scale at a competitive price. Nevertheless, this method could still be used to generate energy from domestic and agricultural waste in a clean way.

One method of generating hydrogen from biomass begins with processing the organic materials at high temperatures, but without combustion. When combined with oxygen and steam, the reaction results in carbon monoxide, carbon dioxide and hydrogen gas. This gasification process can take the carbon monoxide that is produced and combine it with additional steam to produce additional hydrogen and carbon dioxide, which is recycled through the natural plant respiration cycle and generate additional biomass. Alternative options may involve biological agents, such as anaerobic bacteria or fermentation, or pyrolysis, which uses the same gasification process, but without the presence of oxygen. Research in this field is suggesting new ways to improve efficiency and increase the implementation of hydrogen generation from biomass. Along with analysis that shows that biomass feedstock usable for energy production should be plentiful, the future usage of hydrogen production techniques related to biomass should continue to grow. Looking toward further opportunities, research being conducted promises to develop bacterial and microbial actors that increase production efficiency, while additional efforts focus on methods to lower both production costs and the costs of obtaining the feedstock.

Electrolysis (water-electrolysis): Water electrolysis is the process whereby water is split into hydrogen and oxygen through the application of electrical energy, as indicated in Equation (6) below. Typically, a water electrolysis unit consists of an anode, a cathode separated with an electrolyte, and a power supply. The electrolyte can be made of an aqueous solution containing ions, a proton exchange membrane (PEM) or an oxygen ion-exchange ceramic membrane. A direct current (DC) is applied from the negative terminal of the DC source to the cathode (seat of the reduction reaction), where the hydrogen is produced. At the anode, the electrons produced by the electrochemical reaction return to the positive terminal of the DC source.

For the case of water electrolysis in an acid aqueous electrolyte, the processes that occur at the anode and the cathode are described, respectively, by Eqs. 1 and 2

$$
\begin{array}{ll}
\mathrm{H}_{2} \mathrm{O} \rightarrow \frac{1}{2} \mathrm{O}_{2}+2 \mathrm{H}^{+}+2 e^{-} E^{0} & \text { Eq } 1 \\
2 \mathrm{H}^{+}+2 e^{-} \rightarrow \mathrm{H}_{2} E^{0} & E q 2
\end{array}
$$


The half-reactions occurring at the cathode and the anode respectively can be written as:

$$
\begin{array}{ll}
2 \mathrm{H}_{2} \mathrm{O}+2 e^{-} \rightarrow \mathrm{H}_{2}+2 \mathrm{OH}^{-} & \mathrm{Eq} 3 \\
2 \mathrm{HO}^{-} \rightarrow \frac{1}{2} \mathrm{O}_{2}+\mathrm{H}_{2} \mathrm{O}+2 e^{-} E^{0} & \mathrm{Eq} 4
\end{array}
$$

The global reaction for the two cases is:

$$
\mathrm{H}_{2} \mathrm{O} \rightarrow \mathrm{H}_{2}+\frac{1}{2} \mathrm{O}_{2} \quad \mathrm{Eq} 5
$$

Electrolysis of water is not a spontaneous phenomenon because the standard global reaction potential is negative. Therefore, it needs an extra intervention (power source) and the global reaction can be written as:

$\mathrm{H}_{2} \mathrm{O}+$ electricity $\rightarrow \mathrm{H}_{2}+\frac{1}{2} \mathrm{O}_{2} \quad$ Eq 6

Electrolysis of pure water requires excess energy in the form of overpotential to overcome various activation barriers. Without the excess energy, the electrolysis of pure water occurs very slowly or not at all. This is in part due to the limited self-ionization of water. Pure water has an electrical conductivity of about one-millionth that of seawater. Many electrolytic cells may also lack the requisite electrocatalysts. The efficiency of electrolysis is increased through the addition of an electrolyte (such as a salt, an acid or a base) and the use of electrocatalysts.

Water electrolysis has some unique qualities. Electrolysis could be used for hydrogen production at any place around the globe. The only requirements of this production are electricity and water where the production rate/capacity could be tuned for a certain demand at any place. With regard to the characteristics of water electrolysis, this method is capable of producing absolutely sustainable and clean hydrogen, also oxygen can be obtained for hospitals and world's water ways remediate hypoxia issues. This goal can be achieved only if the required electricity is obtained from an emission-free method such as wind, solar, geothermal systems, ocean wave or other renewable and green sources. [26].

\section{HYDROGEN STORAGE}

Hydrogen gas has a good energy density by weight, but poor energy density by volume as against hydrocarbons; hence it requires a large storage facility [32]. Storage of Hydrogen gas is one of the key regions where huge advancements are required to hasten the utilization of hydrogen in transportation, refining, power generation applications and in chemical industries. There are several ways of storing hydrogen, but the widely recognized methods are: High-pressure storage in the gaseous form, very low-temperature storage in the liquid form and hydride-based storage in the solid form [11].

\subsection{Hydrogen stored as Compressed gas in High-pressure tanks}

The easiest way to decrease the volume of a gas, at constant temperatures, is to increase its pressure (Boyle's law). Storage of hydrogen gas typically requires high-pressure tanks (200 to 350 bar cylindrical tank pressure), although systems with at least 700 bar capacity are currently under development [33]. These cylinders/tanks are being made from (i) steel (ii) Aluminum core encased with fiberglass and (iii) Plastic core encased with fiberglass. Compressed hydrogen storage systems have been demonstrated in hundreds of prototype fuel cell vehicles and are available commercially at low production volumes [28]. While compressed hydrogen typically is stored at near-ambient temperatures, "cold" (sub-ambient but greater than $150 \mathrm{~K}$ ) and "cryogenic" (150 K and below) compressed hydrogen storage are being investigated due to the higher hydrogen densities that can be achieved at reduced temperatures [28]

\subsection{Hydrogen Stored as Liquid in tanks}

Another industrial technique for storing maximum hydrogen in a restricted volume is to convert hydrogen gas to liquid hydrogen by cooling it to a very low temperature.

Hydrogen turns into a liquid when it is cooled to a temperature below $-252.87^{\circ} \mathrm{C}$. At $-252.87^{\circ} \mathrm{C}$ and 1.013 bars, liquid hydrogen has a density of close to $71 \mathrm{~kg} / \mathrm{m}^{3}$ [11]. At this pressure, $5 \mathrm{~kg}$ of hydrogen can be stored in a $75-$ litre tank. 
In order to maintain liquid hydrogen at this temperature, tanks must be perfectly isolated. Currently, storing hydrogen in the liquid form is being reserved for certain special applications, in high-tech areas such as space travel [11].

\subsection{Hydrogen stored as Solid}

The storage of hydrogen in solid form that is stored in another material is also a promising avenue of research [35]. Methods for storing hydrogen in solid form are techniques involving absorption or adsorption mechanisms of hydrogen by a material [31]. One example is to form solid metallic hydrides through the reaction of hydrogen with certain metal alloys. This absorption is the result of the reversible chemical combination of hydrogen with the atoms that comprise these materials. The most promising materials are composed of magnesium and alanates. Only a low mass of hydrogen can be stored in these materials, which is currently the major downside of this technology [31]. In fact, the best materials currently generate a ratio of hydrogen weight to the total weight of the tank of not more than 2 to $3 \%$.Before considering large-scale applications, it is also important to master certain key parameters such as kinetics (cell performance), the temperature and pressure of the charge and discharge cycles of hydrogen in these materials [34], 2019.

\section{DISCUSSIONS}

\subsection{Hydrogen Application}

[35] revealed that hydrogen is one of the key starting materials used in the chemical industry with an annual worldwide production of about 50 million tons, currently, the largest amount $(\approx 95 \%)$ of the total manufactured hydrogen is consumed mainly by two industrial segments: the chemical sector, accounting for $65 \%$ of the market share (ammonia and methanol synthesis $\approx 63 \%$; liquid hydrocarbons and higher alcohols synthesis $\approx 2 \%$ ) and the refining sector, which accounts for $30 \%$ of the market share (hydrotreating and hydrocracking processes for obtaining high-grade petrochemical products). The other present uses, with $\approx 5 \%$ of the total consumption, include the food industry (sorbitol and fat processing), the metallurgical industry (direct reduction of iron ore), the semiconductor industry and so on. Post covid-19 lockdown, there will be more awareness, demand and investment for hydrogen economy most especially in transport and industrial sectors as fuel source. Covid-19 pandemic has automatically reset world energy consumption toward eco-friendly clean energy that is hydrogen economy. Global environment will sustain natural balance for healthy and clean atmosphere /earth as experienced during the Covid-19 lock down with hydrogen economy.

\subsection{The Economic and Environment Significance of Hydrogen gas energy as a viable fuel option post Covid-19 Pandemic}

Australia, Germany Norway, Denmark, United States, Canada, South Korea and Japan have made massive investment toward hydrogen economy, more seriously energy and environmentally concern countries are also actively developing and investing their own [32] because the future of world energy consumption is toward hydrogen economy. In order for hydrogen to be considered an economically viable fuel option it must be produced and delivered at a stable price that is competitive with the current price of refine petroleum (gasoline /diesel). Furthermore, the cost of hydrogen economy infrastructure development must be considered, the availability and accessibility of hydrogen must be realized through production and distribution capacity. Some existing pipelines could even be modified to support hydrogen economy for distribution. However long-distance distribution network may not be required as hydrogen can be produced regionally where it is needed. One major benefit of hydrogen is that it can be produced from a variety of primary sources and different production process as earlier discussed; therefore, accessibility of hydrogen could be almost anywhere in the world. Another benefit of hydrogen over other fuel option is that after combustion/reaction product is water vapour there is no carbon foot print or greenhouse gases. The world will be in its natural state as experienced during covid-19 locked down. Using hydrogen as feasible fuel option will not change our transport system as hydrogen can be used as fuel directly in an internal combustion engines not much different from engines used with gasoline [36].

As viable fuel option for industrial and transport sector, hydrogen has peculiar properties which include rapid burning speed which enhances performance of engines, high octane number with non-toxicity and no ozone forming potential. A hydrogen engine is easy to start in extreme cold weather condition because its remain in gaseous state until it reaches a low temperature such as $20 \mathrm{~K}$ [37]. Although engine combustion products of hydrogen are clean; consisting of water 
and little amount of nitrogen oxides $\left(\mathrm{NO}_{\mathrm{X}}\right)$, since there is little or no presence of volatile organic compounds a steady state of natural balance will always be achieved where relative low ozone exist naturally in the troposphere of the Earth. Production hydrogen from electrolysis from splitting of water can result to elevated oxygen level which may enhance good breathing for land and aquatic life. With hydrogen as fuel option the earth will always be its fresh pure state and human health will not threaten. Life span of people where hydrogen economy is entrenched is likely to increase. The planet can become hopeful of climate neutrality in the years ahead with hydrogen economy. A hydrogen economy is a long terms goal of many nations, can potentially confer prosperity and be a solution to energy security, along with financial, environmental and health benefits to the world.

\section{CONCLUSION}

No doubt Post covid-19 pandemic will be a time for global energy shift toward hydrogen economy. Hydrogen economy will make the world better place for improved public health living, the environment will be devoid anthropogenic pollutions from fossil fuel and there will be sustainable earth balance. Hydrogen economy comes with increase in oxygen level in atmosphere. Life span of living matter may likely to improve. Hydrogen economy will lead to decarbonization of the atmosphere as there are no carbon footprint in the hydrogen engine emissions. With hydrogen economy there is no political power tussle and economic unrest as hydrogen fuel could be produce anywhere in the world. Hydrogen economy has the potential of more job's creation and other economic benefits. It can result to stable, inexhaustible energy supply. Electricity becomes cheap and energy is readily accessible. The world will be a better place and relatively at peace. Hydrogen economy is the only energy resources that can meet world energy needs, its emission goal and find appropriate solution for region of the world. Hydrogen economy is a more reliable and resilient energy system.

\section{REFERENCE}

[1] Chen B, Liang H, Yuan X, Hu Y, Xu M, Zhao Y, et al. Roles of meteorological conditions in COVID-19 transmission on a worldwide scale. medRxiv 2020.

[2] Press, Roman J.; Santhanam, K. S. V.; Miri, Massoud J.; Bailey, Alla V.; Takacs, Gerald A. (2008). Introduction to hydrogen Technology. John Wiley \& Sons. ISBN 978-0-471-77985-8.

[3] Wang J, Tang K, Feng K, Lv W. High Temperature and High Humidity Reduce the Transmission of COVID19. Available at SSRN 35517672020

[4] Bauwen M, Compernolle S,Stavrakou T,Muller JF, van Gent J, Eskes H, Levelt, R vander A. Veefkind J.P, Veefkind J, Huan Yu, C. Zehner. Impact of coronavirus outbreak in NO2 pollution assessed using TRIPOMI and OMI observations. American Geophysical Union.2020.

[5] United States Department of Energy: National Hydrogen Energy Roadmap, Production, Delivery, Storage, Conversion, Applications, Public Education and Outreach (2002). Washington DC

[6] Zanganeh KE, Shafeen A. A novel process integration, optimization and design approach for large-scale implementation of oxy-fired coal power plants with CO2 capture. Int J Greenhouse Gas Cont 2007; 1:47.

[7] Shaikh F, Ji Q, Fan Y. Evaluating China's natural gas supply security based on ecological network analysis. J Clean Prod 2016;139:1196e206.

[8] Lin B, Xu M. Regional differences on CO 2 emission efficiency in metallurgical industry of China. Energy Pol 2018; 120:302e11.

[9] Tilt B. China's air pollution crisis: Science and policy perspectives. Environ Sci Pol 2019;92:275e80

[10] Meher LC, Sagar DV, Naik SN. Technical aspects of biodiesel production by transesterification d a review. Renew Sustain Energy Rev 2006;10:24 
[11] Balat Mustafa. Potential importance of hydrogen as future solution to environmental and transport problems. International Journal of Hydrogen Energy 33 (2008) 4013-4029

[12] Campen A, Mondal K, Wiltowski T. Separation of hydrogen from syngas using a regenerative system. Int J Hydrogen Energy 2008;33:332

[13] Prince-Richard S, Whale M, and Djilali N (2005). A Techno-economic Analysis Of Decentralized Electrolytic Hydrogen Production for Fuel Cell Vehicles. International Journal of Hydrogen Energy; 30(11):1159-1179

[14] Australian Renewable Energy Agency. Hydrogen Energy 16 December 2019. arena.gov.au/renewableenergy/hydrogen/.

[15] Suban M, Tug ek J, Uran M. Use of hydrogen in welding engineering in former times and today. J Mater Process Technol 2001;119:193 Source of hydrogen

[16] Mariolakos I, Kranioti A, Markatselis E, Papageorgiou M. Water, mythology and environmental education. Desalination 2007;213:141.

[17] Norbeck JM, Barth MJ, Farrell JA, Heffel JM. Development and evaluation of a hydrogen fuel power plant for hybridelectric vehicle - phase 2. Final report to the South Coast Air Quality Management District under contract 95073, project 7; December, 1997.

[18] Berry, G. D., A. D. Pasternak, G. D. Rambach, J. R. Smith, and R. N. Schock. 1996. Hydrogen as a future transportation fuel. Energy 21:289-303.

[19] Plass Jr., J. H., F. Barbõ r, H. P. Miller, and T. N. VeziroÆglu. 1990. Economics of hydrogen as a fuel for surface transportation. Int. J. Hydrogen Energy 15:663-668.

[20] Utgikar V, Thiesen T. Life cycle assessment of high temperature electrolysis for hydrogen production via nuclear energy. Int J Hydrogen Energy 2006; 31:939

[21] Charvin P, Stephane A, Florent L, Gilles F. Analysis of solar chemical processes for hydrogen production from water splitting thermochemical cycles. Energy Conver Manage 2008; 49:1547.

[22] Granovskii M, Dincer I, Rosen MA. Exergetic life cycle assessment of hydrogen. production from renewable. J Power Sources 2007; 167:461.

[23] Tarnay DS. Hydrogen production at hydro-power plants. Int J Hydrogen Energy 1985; 10:577.

[24] Sigurvinsson J, Mansilla C, Arnason B, Bontemps A, Marechal A, Sigfusson TI, et al. Heat transfer problems for the production of hydrogen from geothermal energy. Energy Conver Manage 2006; 47:3543.

[25] Häussinger, Peter; Lohmüller, Reiner; Watson, Allan M. (2011). Hydrogen: Properties and Occurrence. Ullmann's Encyclopedia of Industrial Chemistry doi: $10.1002 / 14356007 . a 13$ 297.pub2. ISBN $\underline{\text { 978-3-527-30673-2. }}$

[26] Mazloomi, K., and Gomes, C. (2012). Hydrogen as an energy carrier: Prospects and challenges. Renewable and Sustainable Energy Reviews, 16(5), 3024-3033. https://doi.org/10.1016/j.rser.2012.02.028

[27] International Energy Agency. World energy outlook 2017. Available from: https://webstore.iea.org/worldenergy-outlook-2017.

[28] Sharma, S., and Ghoshal, S. K. (2015). Hydrogen the future transportation fuel: From production to applications. Renewable and Sustainable Energy Reviews, 43, 1151-1158. 
[29] Deiana, P., Pettinau, A., and Tola, V. (2007). Hydrogen production from coal gasification in updraft gasifier with syngas treatment line. 1 .

[30] Acar, C., \& Dincer, I. (2014). Comparative assessment of hydrogen production methods from renewable and non-renewable sources. International Journal of Hydrogen Energy, 39(1), 1-12. https://doi.org/10.1016/j.ijhydene.2013.10.060

[31] Allen JA, Glenn M, Hapugoda P, Stanger R, O'Brien G, Donne SW, (2018) 'An investigation of mineral distribution in coking and thermal coal chars as fuels for the direct carbon fuel cell', Fuel, 217 11-20.

[32] Abe JI, Popoola API, Ajenifuja E, Popoola OM. Hydrogen Energy, Economy and Storage: Review and Recommendation. International Journal of Hydrogen Energy 2019. 44:44:15072-86

[33] Acar, C., and Dincer, I. (2017). Energy and exergy analyses of a novel photoelectrochemical hydrogen production system. International Journal of Hydrogen Energy, 42(52), 30550-30558. https://doi.org/10.1016/j.ijhydene.2017.10.008

[34] Gronewold N. Momentum builds for hydrogen fuel in Japan, Australia. 2019. www.scientificamerican.com/article/ momentum-builds-for-hydrogen-fuel-in-japan-australia/.

[35] Vozniuk, O., Tanchoux, N., Millet, J., Albonetti, S., Renzo, F. Di, \& Cavani, F. (2019). Spinel Mixed Oxides for Chemical-Loop Reforming: From Solid State to Potential Application. In Horizons in Sustainable Industrial Chemistry and Catalysis (1st ed., Vol. 178). Elsevier B.V. https://doi.org/10.1016/B978-0-444$\underline{64127-4.00014-8}$

[36] Balat Mustafa. Current alternatives engines fuels. Energy sources part a 2005; 27: 569

[37] Ma J, Su Y, Zhou Y, Zhang Z, Simulation and Prediction of the Performance of Vehicle Hydrogen engines. International Journal of Hydrogen Engines.2003; 28:127

[38] Dincer, I., \& Acar, C. (2014). Review and evaluation of hydrogen production methods for better sustainability. International Journal of Hydrogen Energy, 40(34), 11094-11111. https://doi.org/10.1016/j.ijhydene.2014.12.035 